\title{
IMPLEMENTASI PEMBELAJARAN ILMU PENGETAHUAN SOSIAL (IPS) DALAM MEMBENTUK KARAKTER SISWA
}

\section{THE IMPLEMENTATION OF SOCIAL SCIENCE LEARNING (IPS) IN BUILDING STUDENTS' CHARACTERS}

\author{
Hermanto $^{1}$, Muhammad Japar ${ }^{2}$, Erry Utomo ${ }^{3}$ \\ ${ }^{1}$ Prodi Pendidikan Dasar Pascasarjana Universitas Negeri Jakarta, ${ }^{2,3}$ Pendidikan Dasar \\ Universitas Negeri Jakarta \\ 1,2,3 J1. Rawamangun Muka, Jakarta Timur, Daerah Khusus Ibukota Jakarta \\ Email: pbmanto92@gmail.com ${ }^{1}$, mjapar12@gmail.com ${ }^{2}$, erry30.utomo@gmail.com ${ }^{3}$
}

\begin{abstract}
Abstrak
Penelitian ini bertujuan untuk mengetahuai implementasi pembelajaran Ilmu Pengetahuan Sosial (IPS) dalam membentuk karakter siswa dan mengetahui pelaksanaan/penerapan pendidikan karakter siswa SD Negeri Karang Asih 12 Bekasi dan SD Negeri Ganda Mekar 01 Bekasi. Penelitian ini merupakan penelitian deskriptif dengan menggunakan pendekatan kualitatif. Subyek penelitin ini adalah Guru Ilmu Pengetahuan Sosial (IPS) dan Siswa SD Kelas V dengan teknik pengumpulan data yaitu wawancara, observasi, dokumentasi, dan content analysis, validitas data menggunakan triangulasi data dan triangulasi metode. Hasil penelitian menunjukan bahwa proses implementasi atau penerapan pembelajaran Ilmu Pengetahuan Sosial (IPS) dilaksanakan dengan baik sesuai dengan tujuan pendidikan nasional kemudian melaksanakan pendidikan karakter atau membentuk karakter siswa sekolah dasar sesuai dengan karakter budaya masyarakat daerah setempat.
\end{abstract}

Kata Kunci: Pembelajaran, Ilmu Pengetahuan Sosial (IPS), Karakter

\begin{abstract}
This study aims to find out the implementation of learning Social Sciences (IPS) in building the students' character of students and knowing the implementation/application of character education of Karang Asih Elementari School 12 Bekasi and SD Negeri Mekar 01 Bekasi. This research is a descriptive study using a qualitative approach. The research subjects were social science teachers (IPS) and the $5^{\text {th }}$ grade students'of elementary school which used data collection techniques namely interview, observation, documentation, and content analysis. Data validity used data triangulation and method triangulation. The results of the study showed that the process of implementing social sciences (IPS) learning is carried out well in accordance with the objectives of national education and then implementing character education or building the character of elementary school students in accordance with the local cultural character of the area.
\end{abstract}

Keywords: Learning, Social Sciences (IPS), Character

\section{Pendahuluan}

Ilmu pengetahuan sosial (IPS) merupakan mata pelajaran yang memiliki peranan penting dalam membentuk warga negara yang baik, maka pembelajaran ilmu pengetahuan sosial (social studies), sangatlah penting pada jenjang pendidikan dasar dimana pendidikan dasar merupakan peletakan dasar/fondasi pemahaman dan keilmuan tentang bagaimana hidup bersosial karena di sekolah siswa yang datang dari lingkungan yang berbeda-beda, sisi lain dari itu juga bahwa kepedulian terhadap lingkungan sosial atau memiliki pengetahuan dan pemahaman tentang sosial itu bagian dari pada nilai- 
nilai pendidikan karakter bangsa. Seperti yang dijelaskan diatas, tentu pengenalan dan penguatan ilmu pengetahuan sosial terus dikembangkan sedalam mungkin untuk membentuk karakter siswa di sekolah. Ada tiga tujuan pembelajaran IPS kepada siswa, yaitu agar setiap siswa menjadi warga masyarakat yang baik, melatih siswa berkemampuan berfikir matang untuk menghadapi dan memecahkan masalah-masalah sosial, dan agar siswa dapat mewarisi dan melanjutkan budaya dan cita-cita bangsa Indonesia (Direktorat Pendidikan Lanjutan Pertama, 200; 154).

Menurut Susanto (2016: 138) hakikat ilmu pengetahuan sosial adalah mengembangkan konsep pemikiran yang berdasarkan suatu realita kondisi sosial yang ada di lingkungan siswa, sehingga dengan memberikan pendidikan IPS diharapkan dapat melahirkan warga negara yang baik dan bertanggung jawab terhadap bangsa dan negaranya.

Sumaatmada (1984: 94) menyatakan bahwa studi sosial (social studies) bukan merupakan bidang keilmuan atau disiplin akademis, tetapi lebih dari itu yang merupakan suatu bidang pengkajian tentang masalah dan fenomena sosial, tentunya studi sosial lebih bersifat praktis dan dinamis dibandingkan akademik teoritis. Dengan demikian tujuan pendidikan ilmu pengetahuan sosial ini dikembangkan dan diimplementasikan atas dasar pemikiran bahwa pendidikan ilmu pengetahuan sosial adalah suatu disiplin ilmu. Oleh karena demikian pendidikan ilmu pengetahuan sosial harus mengacu pada tujuan pendidikan nasional.

Oktapiani \& Rustini (2013: 121) menyatakan pendidikan sebagai salah satu upaya dalam rangka meningkatkan kualitas menjadi lebih baik, pendidikan ini menuntun agar mempersiapkan diri kita dalam menghadapi carut marut bangsa dengan berbagai masalah termasuk menghadapi perkembangan dan tantangan teknologi di masa sekarang dan masa yang akan datang adalah pembelajaran IPS. Kurikulum 2006 dalam tingkat sekolah dasar menyatakan bahwa pendidikan ilmu pengetahuan sosial bertujuan untuk mengenal konsep-konsep yang berkaitan dengan kehidupan masyarakat dan lingkungan sosial, memiliki kemampuan dasar untuk berfikir rasional, logis, dan kritis, rasa ingin tahu, inkuiri, memecahkan masalah dan keterampilan dalam kehidupan sosial, memiliki komitmen dan kesadaran tinggi terhadap nilai-nilai sosial dan kemanusiaan yang di ajarkan, memiliki kemampuan berkomunikasi, bersahabat dan bekerja sama serta berkompetisi dalam masyarakat yang majemuk di tingkat lokal, nasional dan global.

Penguatan pendidikan karakter di era saat ini merupakan hal yang paling penting untuk dilakukan mengingat banyaknya peristiwa yang menunjukan terjadinya krisis moral baik dikalangan anak-anak, remaja, maupun orang tua, di sekolah maupun di luar sekolah. Oleh karena itu, penguatan dan pemahaman tentang pendidikan karakter perlu dilaksanakan dan diimplementasikan mulai dari lingkungan, keluarga, sekolah dan bahkan dalam masyarakat luas.

Menurut Lickona (2015) pendidikan karakter adalah pendidikan budi pekerti yaitu yang melibatkan aspek pengetahuan (cognitve), perasaan (feeling), dan tindakan (action). Jadi pendidikan karakter tanpa melibatkan ketiga aspek ini pendidikan karakter tidak akan efektif sesuai dengan cita-cita bangsa. Jadi pendidikan karakter merupakan salah satu upaya yang harus dilaksanakan di sekolah untuk membina karakter serta moral yang sesuai dengan norma dan nilai-nilai dari Tuhan Yang Maha Esa. Kemudian selanjutnya menurut Jamal Ma'ruf (2011: 31) bahwa pendidikan karakter adalah segala sesuatu yang dilakukan oleh pendidik dalam mempengaruhi dan membentuk karakter siswa. Pendidik membantu dalam membentuk watak dan perilaku siswa dengan cara 
memberikan contoh dan keteladanan yang baik, cara berbicara atau menyampaikan materi yang baik dan bahkan dalam kepeduliaan terhadap sosial kemasyarakatan.

Maka demikian pemahaman siswa terhadap ilmu pengetahuan sosial itu penting sebagai bentuk implementasi dari pendidikan karakter bangsa indonesia, agama, pancasila dan tujuan pendidikan nasional yang tentunya dijalankan lewat proses pembelajaran yang berlangsung di sekolah, baik sekolah negeri maupun sekolah swasta yang bertujuan untuk membangun sumber daya manusia di Indonesia.

Hal tersebut juga sejalan dengan amanat UU No. 20 tahun 2003 Tentang Sistem Pendidikan Nasional pasal 3 yang menjelaskan fungsi pendidikan nasional adalah mengembangkan kemampuan dan membentuk watak serta peradaban bangsa yang bermartabat dalam rangka mencerdaskan kehidupan bangsa, dan tujuan pendidikan nasional yaitu untuk mengembangkan potensi siswa agar menjadi manusia yang beriman dan bertakwa kepada Tuhan Yang Maha Esa, berakhlak mulia, sehat, berilmu, cakap, kreatif mandiri dan menjadi warga negara yang demokratis dan bertanggung jawab. Implikasi dari undang-undang ini adalah, pendidikan disetiap satuan pendidikan termasuk sekolah dasar harus diselenggarakan secara terprogram dan sistematis yang akan mengarah kepada pencapaian tujuan pendidikan nasional.

Nilai-nilai pendidikan karakter yang di maksud adalah yang bersumber dari agama, pancasila, budaya dan tujuan pendidikan nasional, yaitu: (1) religius, (2) jujur, (3) toleransi, (4) disiplin, (5) kerja keras, (6) kreatif, (7) mandiri, (8) demokratis, (9) rasa ingin tahu, (10) semangat kebangsaan, (11) cinta tanah air, (12) menghargai prestasi, (13) bersahabat/komunikatif, (14) cinta damai, (15) gemar membaca, (16) peduli lingkungan, (17) peduli sosial, dan (18) tanggung jawab (Puskurbuk, 2011: 3).

Berdasarkan studi awal tentang pelaksanaan pelajaran IPS dalam membentuk Karakter siswa di 2 sekolah dasar negeri di wilayah Kecamatan Cikarang Barat Kota Bekasi adalah kebanyakan guru dalam mengajar di kelas lebih berfokus pada pengembangan kognitif siswa, maksudnya guru lebih memprioritaskan pada materi pembelajaran, sementara untuk pengembangan nilai karakter hanya disampaikan pada rencana pelaksanaan pembelajaran (RPP) dan silabus. Berdasarkan studi awal tersebut dan latar belakang masalah pada penelitian ini, peneliti tertarik meneliti tentang: 1) bagaimana implementasi dari pelajaran IPS dalam membentuk karakter siswa, dan 2) bagaimana pelaksanaan pendidikan karakter dalam kegiatan pembelajaran dalam 2 (dua) sekolah dasar tersebut.

Melihat fakta yang dijelaskan diatas baik secara yuridis, teoritis dan maupun empiris yang menyatakan bahwa pentingnya implementasi/penerapan pembelajaran IPS dalam pelaksanaan proses pembelajaran di sekolah dasar supaya untuk membentuk karakter siswa. Dimana hasil dari implementasi pembelajaran ilmu pengetahuan sosial itu akan menjadi bekal di dalam kehidupan sehari-hari. Kemudian dalam penelitian Enok Muryani dan Helius Syamsudin, menyatakan bahwa ilmu pengetahuan sosial yang menjadi dasar penting dalam mengembangkan intelektual, emosional, kultural, dan sosial siswa yang mampu menumbuhkembangkan cara berfikir, bersikap dan berperilaku yang bertanggungjawab terhadap individu, masyarakat dan warga dunia (Wicaksono, 2016: 59). Sangat jelas bahwa pembelajaran ilmu pengetahuan sosial dirancang untuk mengembangkan kemampuan analisis terhadap kondisi sosial masyarakat yang hidup secara dinamis. 


\section{Metode Penelitian}

Penelitian ini termasuk jenis penelitian deskriptif dengan menggunakan pendekatan kualitatif. Menurut Sugiyono (2018: 9) penelitian kualitatif merupakan metode penelitian yang berlandaskan pada filsafat postpositivisme, digunakan untuk meneliti pada kondisi obyek yang alamiah, (sebagai lawannya adalah eksperimen) dimana peneliti adalah sebagai instrumen kunci, teknik pengumpulan data dilakukan secara triangulasi (gabungan), analisis data bersifat induktif/kualitatif, dan hasil penelitian kualitatif lebih menekankan makna dari pada generalisasi. Sementara itu Bog dan Taylor dalam Moleong (2014:4) menjelaskan bahwa prosedur penelitian yang menghasilkan data deskriptif berupa kata-kata tertulis atau lisan dari orang-orang atau pelaku yang diamati. Kemudian Sukmadinata \& Syaodih (2013: 54) menekankan bahwa penelitian deskriptif adalah suatu metode penelitian yang ditujukan untuk menggambarkan fenomena-fenomena yang ada, yang berlangsung pada saat ini atau pada saat lampau serta tidak mengadakan manipulasi atau perubahan pada variabelvariabel bebas, tetapi menggambarkan suatu kondisi dengan apa adanya.

Penelitian ini dilaksanakan di 2 (dua) SD Negeri yang terletak di Kecamatan Cikarang Barat Kota Bekasi yaitu SD Negeri Karang Asih 12 Bekasi dan SD Negeri Ganda Mekar 01 Bekasi dengan sumber data penelitian yaitu informan (Kepala Sekolah, Guru IPS, Peserta Didik kelas V dan Karyawan Sekolah), dokumen (buku tes, silabus, RPP), tempat dan peristiwa (kelas dan kegiatan pembelajaran). Teknik pengumpulan data menggunakan wawancara yang mendalam, observasi, dokumentasi, dan content analysis, validitas data menggunakan triangulasi data dan triangulasi metode sehingga terjadi secara elaboratif. Teknik analisis data yang digunakan adalah analisis sebelum lapangan, analisis selama di lapangan (reduksi data, penyajian data dan verifikasi) dan penarikan simpulan. Adapun indikator-indikator yang digunakan dalam menyusun instrumen penelitian berdasarkan perencanaan (planning), pengorganisasian (organizing), pelaksanaan (actuating), dan pengawasan (controlling).

\section{Hasil Penelitian dan Pembahasan}

Dalam mendukung proses pembelajaran ilmu pengetahuan sosial adalah guru merupakan faktor penting dan penentu dalam keberhasilan siswa dalam menerima transformasi ilmu pengetahuan baik pada saat belajar di kelas maupun di luar kelas, guru kemudian mampu memberikan banyak strategi dan cara kepada siswa dalam menentukan pilihan dan serta menentukan arah dan tujuan kedepannya, salah satunya adalah pembentukan karakter siswa yang sangat mendasar karena guru berperan langsung dalam mengembangkan potensi yang dimiliki oleh siswa sebagai salah satu keberhasilan guru maupun siswa dalam pelaksanaan pendidikan karakter di sekolah sehingga perlu adanya penguatan pengetahuan tentang pendidikan sosial (social studies). Sesuai dengan hasil wawancara (W2.W3.No.3) dan observasi dengan menggunakan instrumen penelitan dan pedoman observasi yang disusun berdasarkan indikator-indikator tertentu terhadap sejumlah guru ilmu pengetahuan sosial di kedua sekolah tersebut diketahui bahwa pendidikan karakter belum dipahami oleh semua guru disekolah, sehingga implementasi/penerapan ilmu pengetahuan sosial dalam kelas maupun di luar kelas dalam membentuk karakter siswa belum berjalan dengan maksimal.

Menurut Lickona (2015) karakter dikembangkan melalui tahap pengetahuan (knowing), pelaksanaan (acting), dan kebiasaan (habit). Karena itu, seseorang dikatakan berkarakter baik manakala dalam kehidupan nyata sehari-hari memiliki tiga kebiasaan, 
yaitu: memikirkan hal yang baik (habits of mind), menginginkan hal yang baik (habits of heart), dan melakukan hal yang baik (habits of action). Melihat pernyataan tersebut bahwa ternyata memang pengetahuan tidak selalu menjadi tolak ukur bahwa karakter siswa itu bisa dan mampu merubah sikap dan karakternya tetapi memang perlu adanya pelaksanaan, kebiasaan sehingga ilmu pengetahuan sosial siswa dalam membentuk karakter tercapai dengan harapan, semakin tinggi sikap kepedulian siswa terhadap sosial maka semakin besar potensi pendidikan karakter yang diterapkan.

Berdasarkan hasil penelitian yang dilakukan oleh peneliti di kedua sekolah tersebut bahwa implementasi pembelajaran IPS yang dilaksanakan di SD Negeri karang Asih 12 Bekasi dan SD Negeri Ganda Mekar 01 Bekasi berjalan dengan baik, ditemukan nilai karakter yang mulai diterapkan dalam proses pembelajaran IPS berlangsung yaitu, dapat dipercaya, disiplin, tekun, kerja keras dan kerjasama. Karena proses pembelajaran ilmu pengetahuan sosial itu penting diterapkan di sekolah dasar sebagai pembentukan karakter dasar para siswa yang akan diimplementasikan dalam kehidupan sehari-hari. Hal ini selaras dengan menurut Oktapiani \& Rustini (2013: 122) tujuan pendidikan IPS dapat dikelompokan kedalam tiga aspek, yaitu: pengembangan kemampuan intelektual siswa, pengembangan kemampuan dan rasa tanggung jawab sebagai anggota masyarakat dan bangsa serta pengembangan diri siswa sebagai pribadi.

Adapun pelaksanaan pendidikan yang berlangsung di kedua sekolah tersebut adalah:

\subsection{Pelaksanaan Pendidikan Karakter dalam Pembelajaran SD Negeri Karang Asih 12 Bekasi dan SD Negeri Ganda Mekar 01 Bekasi}

Pelaksanaan pembelajaran pendidikan karakter dalam sekolah ini menggunakan pendekatan proses belajar siswa secara aktif yang berpusat pada anak, dilakukan melalui berbagai kegiatan di kelas, sekolah, dan masyarakat. Pengembangan nilai-nilai tertentu dilakukan dengan baik seperti kerja keras, jujur, toleransi, disiplin, mandiri, semangat kebangsaan, cinta tanah air, dan gemar membaca dapat melalui kegiatan belajar yang biasa dilakukan oleh guru.

Untuk pengembangan beberapa nilai lain seperti peduli sosial, peduli lingkungan, rasa ingin tahu, dan kreatif memerlukan upaya pengkondisian sehingga siswa memiliki kesempatan untuk memunculkan perilaku yang menunjukan nilai-nilai tersebut. Kemudian guru memberikan pekerjaan rumah atau tugas rumah sebagai bentuk kesadaran siswa terhadap fungsi dan tugasnya sebagai terpelajar. Kegiatan disekolah misalnya melalui kegiatan yang dapat dimasukan ke dalam program sekolah adalah lomba antar kelas tentang lagu bertema cinta tanah air, pergelaran seni, lomba pidato bertema budaya dan karakter bangsa, lomba olahraga antar kelas, lomba kesenian antar kelas, pameran hasil karya siswa dan lomba membuat tulisan. Kegiatan diluar sekolah yaitu melalui kegiatan ekstrakurikuler dan kegiatan lain yang diikuti oleh seluruh atau sebagian siswa, yang dirancang sejak awal tahun pelajaran, dan dimasukkan kedalam kalender akademik. Misalnya kunjungan ketempat yang menumbuhkan rasa cinta terhadap tanah air, menumbuhkan semangat kebangsaan, dan melakukan pengabdian masyarakat untuk menumbuhkan kepedulian sosial.

\subsection{Nilai- Nilai Karakter Dalam Lingkungan SD Negeri Karang Asih 12 Bekasi dan SD Negeri Ganda Mekar 01 Bekasi}

Di dalam proses belajar mengajar juga terdapat kriteria penilaian khusus terhadap sikap dan perilaku siswa lingkungan sekolah. Seperti pada modul pada pelatihan implementasi kurikulum 2013 terdapat format penilaian sikap siswa yang salah satunya adalah sikap individu. Penilaian sikap individu tersebut diantara beriman, 
berakhlak mulia, dan jujur. Nilai-nilai karakter dalam ligkungan SD Negeri Karang Asih 12 Bekasi dan SD Negeri Ganda Mekar 01 Bekasi ini sama-sama melaksanankan 18 nilai-nilai karakter bangsa. Meski hanya beberapa nilai yang sering dilakukan.

\section{Kesimpulan}

Berdasarkan hasil penelitian ini dapat disimpulkan bahwa proses pembelajaran Ilmu Pengetahuan Sosial (IPS) SD Negeri Karang Asih 12 Bekasi dan SD Negeri Ganda Mekar 01 Bekasi telah melaksanakan dengan baik pembelajaran ilmu pengetahuan sosial dalam membentuk karakter siswa dan melaksanakan pendidikan karakter dan atau menerapkan pendidikan karakter budaya dan bangsa dengan memperhatikan karakter budaya daerah setempat.

\section{Daftar Pustaka}

Direktorat Pendidikan Lanjutan Pertama. (2004). Pendidikan Lanjutan Pertama. (2004). Materi Pelatihan Terintegrasi Pengetahuan Sosial. Jakarta: Ditjen Dikdasmen Depdiknas.

Jamal Ma'ruf, A. (2011). Buku Panduan Internalisasi Pendidikan Karakter di Sekolah. Yogyakarta: DIVA Press.

Lickona, T. (2015). Character Matters; Persoalan Karakter, Bagaimana Membantu Anak Mengembangkan Penilaian Yang Baik, Integritas dan Kebajikan Penting Lainnya. Jakarta: PT Bumi Aksara.

Moleong, L. J. (2014). Metodologi Penelitian Kualitatif. Bandung: Remaja Rosdakarya.

Oktapiani, R., \& Rustini, T. (2013). Contextual Teaching and Learning (CTL) Untuk Meningkatkan Kreatifitas Berpendapat Siswa pada Pembelajaran IPS, 5(2). Retrieved from http://ejournal.upi.edu/index.php/eduhumaniora/article/view/2843

Puskurbuk. (2011). Pengembangan Pendidikan Budaya Dan Karakter Bangsa. Jakarta: Gramedia.

Sugiyono. (2018). Metod Penelitian Kualitatif, Kuantitatif dan R\&D. Bandung: Alfabeta.

Sukmadinata, \& Syaodih, N. (2013). Metode Penelitian Pendidikan. Bandung: PT Remaja Rosdakarya.

Sumaatmada, N. (1984). Metodologi Pengajaran Ilmu Pengetahuan Sosial (IPS). Bandung: Penerbit Alumni.

Susanto, A. (2016). Teori Belajar dan Pembelajaran di Sekolah Dasar. Jakarta: Prenadamedia Group.

Wicaksono. (2016). Arini E., \& Kurniana B. (2016). Pelaksanaan Evaluasi Pembelajaran IPS Berbassis KTSP Kelas V. Jurnal Kependidikan Dasar Universitas Negeri Semarang, 7(1). Retrieved from https://journal.unnes.ac.id/nju/index.php/kreatif/article/download/9367/6133 